\title{
Efficacy of conjugated linoleic acid for improving reproduction: A multi-study analysis in early-lactation dairy cows ${ }^{1}$
}

\author{
M. J. de Veth, ${ }^{* 2,3}$ D. E. Bauman, $†$ W. Koch, $\ddagger$ G. E. Mann,§ A. M. Pfeiffer, ${ }^{*}$ and W. R. Butler† \\ *BASF SE, 67056 Ludwigshafen, Germany \\ †Department of Animal Science, Cornell University, Ithaca, NY 14853 \\ ‡HaaPACS GmbH, 69198 Schriesheim, Germany \\ §Division of Animal Sciences, School of Biosciences, University of Nottingham, Sutton Bonington Campus, Loughborough, LE12 5RD, UK
}

\begin{abstract}
The feeding of conjugated linoleic acid (CLA) supplements to early-lactation dairy cows has been shown to decrease milk fat synthesis and possibly improve reproductive performance. However, previously reported studies used too few animals to clearly establish the effect of CLA on reproduction. Our objective was to combine data from these studies to evaluate the association of CLA with time to first ovulation and time to conception using methods of survival analysis and overall success of pregnancy by logistic regression. A database was compiled of individual animal data $(\mathrm{n}=$ 212) from 5 controlled studies in which CLA had been supplemented to early-lactation dairy cows. Survival analysis incorporated both semi-parametric models (Cox proportional hazards) and parametric models (log-normal). The probability of cows becoming pregnant increased in a nonlinear manner as trans-10, cis-12 CLA dose increased, with the optimal dose predicted to be $10.1 \mathrm{~g} / \mathrm{d}$. At the optimal dose, the probability of pregnancy was increased by $26 \%$ compared with those animals receiving no CLA (probability $=91 \%$ and $72 \%$, respectively). Similarly, the log-normal model predicted that time to conception was decreased in a nonlinear manner with increasing trans-10, cis-12 CLA dose. The predicted optimal dose was $10.5 \mathrm{~g}$ of trans-10, cis-12 $\mathrm{CLA} / \mathrm{d}$ and at this dose the median time to conception was decreased by $34 \mathrm{~d}$ when compared with those cows not receiving CLA (117 vs. $151 \mathrm{~d}$ in milk, respectively). The log-normal model was also the best-fit model for time to first ovulation. Overall, this multi-study analy-
\end{abstract}

\footnotetext{
Received October 28, 2008.

Accepted January 21, 2009

${ }^{1}$ Supported by Cornell Agricultural Experiment Station and BASF SE. Also supported in part by the Cooperative State Research, Education and Extension Service, USDA Multistate Project NE-1027. Any opinions, findings, conclusions or recommendations expressed in this publication are those of the authors and do not necessarily reflect the view of the USDA.

${ }^{2}$ Present address: Balchem Corporation, 52 Sunrise Park Rd, New Hampton, NY 10958.

${ }^{3}$ Corresponding author: mdeveth@balchem.com
}

sis demonstrated a strong concordance between the nature of the dose response and the predicted optimal dose of trans-10, cis-12 CLA across the 3 reproductive variables evaluated. These results indicate that reproductive performance of dairy cows may be improved by feeding of CLA supplements during early lactation.

Key words: conjugated linoleic acid, reproduction, fatty acid, survival analysis

\section{INTRODUCTION}

Productive efficiency and milk yield of dairy cows has greatly increased over the past $50 \mathrm{yr}$, but reproductive efficiency has declined (Butler, 2003). Although these changes have coincided, evidence from the United States, Europe, and Australasia suggests that milk yield per se has a relatively minor effect on fertility (Lucy, 2001). However, when the nutrient demands for lactation exceed the nutrient intake, the associated negative energy balance increases the risk of poor reproductive performance in the postpartum dairy cow (Butler, 2000, 2003; Lucy, 2003). The link between negative energy balance and fertility appears to be mediated through endocrine and metabolic signals that control the partitioning of nutrients and reproductive function (Chagas et al., 2007). In an effort to decrease negative energy balance, fat supplements have been used to increase the energy density of the diet, although in general the feeding of fats has not improved energy balance (Staples et al., 1998; Staples and Thatcher, 2006). Interestingly, improved reproductive performance has been reported in some studies when lipid supplements high in polyunsaturated fatty acids were fed; however, results have been inconsistent and many of these studies are not available as peer-reviewed publications (see review by Santos et al., 2008). Nevertheless, it is possible that specific unsaturated fatty acids, when able to bypass rumen alterations and be absorbed from the small intestine, may improve reproductive performance by directly targeting reproductive tissues or by indirect effects mediated via the endocrine system (Staples and Thatcher, 2006). 
Conjugated linoleic acid (CLA) is a generic term for a group of 18-carbon fatty acids with a conjugated double bond that have been shown to influence a range of biological processes. Specifically, the trans-10, cis-12 CLA isomer has been shown to inhibit lipid synthesis in different animal models, with a dose-dependent decrease in milk fat synthesis occurring when supplemented to lactating dairy cows (de Veth et al., 2004; Bauman et al., 2008). Milk fat contributes more than $50 \%$ of the energy in milk and, therefore, the feeding of CLA supplements to the dairy cow during early lactation provides a unique model to evaluate its effect on energy sparing and reproductive performance (Griinari and Bauman, 2006). Studies with CLA in early lactation have observed trends for beneficial effects on reproduction (Bernal-Santos et al., 2003; Castañeda-Gutiérrez et al., 2005); however, the studies were designed to evaluate effects of CLA on lactation performance and individual studies had too few animals to allow definitive conclusions on reproductive performance.

Our objective was to use a multi-study analysis approach to evaluate the effect of CLA supplementation on reproduction variables in early-lactation cows. This evaluation, based on previously reported investigations, included time to first ovulation and conception using methods of survival analysis, and overall success of pregnancy using logistic regression.

\section{MATERIALS AND METHODS}

\section{Data}

The individual animal data were obtained from 5 controlled studies that were conducted in the United States (Bernal-Santos et al., 2003; Castañeda-Gutiérrez et al., 2005, 2007), the Netherlands (de Veth et al., 2005), and the UK (Mann et al., 2007). The studies had evaluated the effect of CLA supplements, with reproductive performance monitored in all studies. A summary of the design of the 5 studies is given in Table 1. Three of the studies used only multiparous cows (Bernal-Santos et al., 2003; Castañeda-Gutiérrez et al., 2005; Mann et al., 2007), whereas 2 studies used both primiparous and multiparous cows (de Veth et al., 2005; Castañeda-Gutiérrez et al., 2007). Across the 5 studies, the CLA dose ranged from 0 to $63.2 \mathrm{~g} / \mathrm{d}$ and this provided 0 to $18.3 \mathrm{~g}$ of trans-10, cis-12 CLA/d. Feeding of the CLA supplements was accomplished by topdressing over the TMR and was initiated between -16 and 21 DIM and terminated between 58 and 140 DIM. Thus, the overall supplementation period ranged from 37 to $154 \mathrm{~d}$ in total (Table 1). To minimize degradation of the CLA isomers in the rumen, all CLA supplements were rumen-protected, with either Ca-salt (Bernal-Santos et al., 2003; Castañeda-Gutiérrez et al.,
2005 ) or lipid-encapsulation technology (de Veth et al., 2005; Castañeda-Gutiérrez et al., 2007; Mann et al., 2007 ) used to protect the CLA. In 3 of the studies, cows were synchronized for estrus and insemination (BernalSantos et al., 2003; Castañeda-Gutiérrez et al., 2005, 2007), while in the other 2 studies breeding at natural estrus commenced from 51 (Mann et al., 2007) and 54 DIM (de Veth et al., 2005), respectively.

The compiled database represented data from 212 individual cows that had been collected from the 5 studies using a standardized spreadsheet. Data from one cow from the Bernal-Santos et al. (2003) study was not available; this cow left the study before recording of reproductive measurements due to reasons not associated with treatment. Data were recorded for cow and study identification, lactation number, treatment, dose of CLA (g/d), dose of trans-10, cis-12 CLA (g/d), and start and end of treatment (DIM). Specific reproductive variables that were recorded were postpartum time of first ovulation and conception, and pregnancy success. Time of first ovulation was estimated based on plasma progesterone levels, with data only available from 2 studies ( $\mathrm{n}=76$; Bernal-Santos et al., 2003; Castañeda-Gutiérrez et al., 2005); other studies either did not measure plasma progesterone (de Veth et al., 2005) or commenced CLA supplementation too late in lactation (Castañeda-Gutiérrez et al., 2007; Mann et al., 2007).

Relationships were analyzed with either total CLA or trans-10, cis-12 CLA dose as the independent variable. Comparing the effect of these 2 independent variables on time of first ovulation and conception and overall pregnancy showed similar relationships. This is not unexpected, because the ratio of trans-10, cis-12 CLA to total CLA was similar in the majority of studies (de Veth et al., 2005; Castañeda-Gutiérrez et al., 2007; Mann et al., 2007). Therefore, relationships reported in the present study are only those with trans-10, cis-12 CLA as the independent variable. Trans-10, cis-12 CLA has been shown to be bioactive in the regulation of lipid metabolism (Bauman et al., 2008) and differences in the dose of trans-10, cis-12 CLA demonstrated the more dramatic changes in plasma hormones related to reproduction (Castañeda-Gutiérrez et al., 2007). The other CLA isomer present in the supplements of the 5 studies was cis-9, trans-11 CLA; many studies have used dietary manipulations to alter the rumen outflow of this isomer, but to our knowledge none have implied effects on reproductive variables.

\section{Statistical Analysis}

All statistical analysis was carried out using JMP Software Version 6.0.3 from SAS (SAS Institute Inc., 
Table 1. Summary of design of the 5 studies used in the analysis to determine effects of conjugated linoleic acid (CLA) on reproductive performance of lactating dairy cows ${ }^{1}$

\begin{tabular}{|c|c|c|c|c|c|}
\hline \multirow[b]{2}{*}{ Study parameter } & \multirow{2}{*}{$\begin{array}{l}\text { Bernal-Santos } \\
\text { et al. (2003) }\end{array}$} & \multicolumn{2}{|c|}{ Castañeda-Gutiérrez et al. } & \multirow{2}{*}{$\begin{array}{c}\text { de Veth } \\
\text { et al. }(2005)\end{array}$} & \multirow{2}{*}{$\begin{array}{c}\text { Mann } \\
\text { et al. }(2007\end{array}$} \\
\hline & & $(2005)$ & $(2007)$ & & \\
\hline Number of cows & 29 & 47 & 45 & 60 & 31 \\
\hline Primiparous & 0 & 0 & 15 & 12 & 0 \\
\hline Multiparous & 29 & 47 & 30 & 48 & 31 \\
\hline \multirow[t]{4}{*}{ Total CLA dose, $\mathrm{g} / \mathrm{d}$} & 0 & 0 & 0 & 0 & 0 \\
\hline & 30.4 & 31.6 & 9.5 & 10 & 15 \\
\hline & & 63.2 & 14.2 & 20 & \\
\hline & & & & 30 & \\
\hline \multirow[t]{4}{*}{ trans-10, cis-12 CLA dose, g/d } & 0 & 0 & 0 & 0 & 0 \\
\hline & 8.8 & 9.2 & 2.4 & 5.0 & 7.5 \\
\hline & & 18.3 & 7.1 & 10.0 & \\
\hline & & & & 15.0 & \\
\hline Treatment application period, d & 154 & 79 & 37 & 91 & 78 \\
\hline Start, mean DIM & -14 & -16 & 21 & 0 & 21 \\
\hline End, mean DIM & 140 & 63 & 58 & 91 & 99 \\
\hline
\end{tabular}

${ }^{1}$ The studies of Bernal-Santos et al. (2003) and Castañeda-Gutiérrez et al. (2005) used calcium salt formulations of CLA with the following 4 CLA isomers: 1) trans-8, cis-10, 2) cis-9, trans-11, 3) trans-10, cis-12, and 4) cis-11, trans-13. The other 3 studies used lipid-encapsulated CLA in which cis-9, trans-11 and trans-10, cis-12 were the predominant CLA isomers.

Cary, NC). The dependent variables were ovulation and pregnancy, analyzed as a categorical variable using logistic regression, and time to first ovulation or conception, analyzed as a censored variable using methods of survival analysis. Independent variables in all models were study and dose of trans-10, cis-12 CLA, with dose modeled as both linear and quadratic terms. The quadratic term for dose effect in the models was centered by subtracting the mean dose to diminish numerical problems resulting from potential collinearity and to allow a meaningful interpretation of the $P$-value of the linear term. Centering does not change the model fit as one can easily verify by retransformation.

Logistic Regression Analysis. The proportion of cows pregnant was modeled using a generalized linear model with binomial distribution and logit link function (SAS Institute Inc., Cary, NC). Interactions were investigated and included in the model if they were statistically significant at the $\alpha=0.1$ level. The statistical model used was

$$
P(\text { preg })=\frac{1}{1+\exp \left(-\beta^{\prime} \mathrm{X}\right)}
$$

where $P$ (preg) is the probability of a cow being pregnant, $\beta^{\prime}$ is the coefficient matrix, and $\mathrm{X}$ is the matrix of the independent variables (i.e., study and dose effects). Model assumptions were checked by plotting residuals (deviances) against the predicted pregnancy.

Survival Analysis. For the analysis of time to conception, any cows that did not conceive were considered to be right censored. A right-censored observation meant that conception had not occurred by the end of study or by the time the subject was no longer observed. Overall, 42 of the total 212 cows were censored for time to conception. Similarly, if the first ovulation was not observed by 80 DIM, the observation was right censored; 8 of the 76 cows [from the Bernal-Santos et al. (2003) and Castañeda-Gutiérrez et al. (2005) studies] were censored.

Both semi-parametric and parametric models were used for the survival analysis. The Cox proportional hazards model is semi-parametric; the effects of the covariates (study and treatment) on the survival times are parametric, but the underlying survivor function (distribution of survival times) need not be specified (Cox, 1972). The Cox model is a robust model because it makes no assumption about the distribution of survival times. However, because the baseline hazard function is not estimated, the Cox model does not completely specify the probability of an event, which may lead to difficulties when validating a model with new data. Therefore, the Cox model was used to assess whether the dose of trans-10, cis-12 CLA influenced the time to first ovulation and time to conception. The Cox model describes the hazard $\left[h_{i}(t)\right]$ of an event (e.g., first ovulation) at any time $t$ as follows:

$$
h_{i}(t)=h_{0}(t) \exp \left(\beta^{\prime} \mathrm{X}\right) .
$$

In this model, $h_{0}(t)$ is an arbitrary nonnegative baseline hazard function, $\mathrm{X}$ is the vector of covariates for individual $i$, and $\beta^{\prime}$ is the vector of unknown regression parameters associated with covariates (Cox, 1972). To 
assess whether the assumption of proportional hazards held in the Cox models, cumulative hazard functions (e.g., cumulative pregnancy rates) by study and dose groups were plotted over time (i.e., DIM) and inspected visually for proportionality. The assessment of proportionality was based both on the original data as well as on assessment of parallel cumulative curves after logtransformation.

Parametric models generate more precise estimates and allow easier interpretation of results (Lee and Go, 1997). For the parametric model, we examined several distributions to approximate the survival data, including exponential, Weibull, and log-normal distributions. Diagnostic failure plots were used to graphically check the appropriateness of these distributions to fit the survival times. From these plots, the best representation for time to ovulation and time to pregnancy was a log-normal distribution, and the linear model took the following form:

$$
\log \left(T_{i}\right)=\beta \mathrm{X}+\log \left(\tau_{i}\right) .
$$

In this model, $\log \left(T_{i}\right)$ is the natural $\log$ of time to ovulation or conception, $\beta \mathrm{X}$ is a linear combination of independent variables (dose of trans-10, cis-12 CLA and study), and $\log \left(\tau_{i}\right)$ is the error term. Various diagnostics were performed for the parametric models developed to ensure that the model assumptions were met. First, the model was run for each study to determine if the log-normal distribution could describe events against the time to either first ovulation or conception. Second, residual plots were evaluated. Residual quartile plots were generated with the Cox-Snell residuals on the $\mathrm{x}$ axis and the Kaplan-Meier estimated quartiles on the y-axis. The fitted parametric model was deemed appropriate, if the resulting curve approximated a straight line.

\section{RESULTS}

In the logistic regression analysis of the effect of CLA supplementation on the probability of cows becoming pregnant, there was an overall effect of CLA $(P=$ $0.008)$, but no study effect $(P=0.14)$ or interaction $(P=0.41)$ between study and dose of trans-10, cis12 CLA. The equation for the dose effect without the study effect is as follows:

$$
P(\text { preg })=\frac{1}{1+\exp \left[-\left(0.959+0.255 \times \text { dose }-0.0125 \times \text { dose }^{2}\right)\right]} .
$$

The probability of cows becoming pregnant was described within the logistic regression approach as a

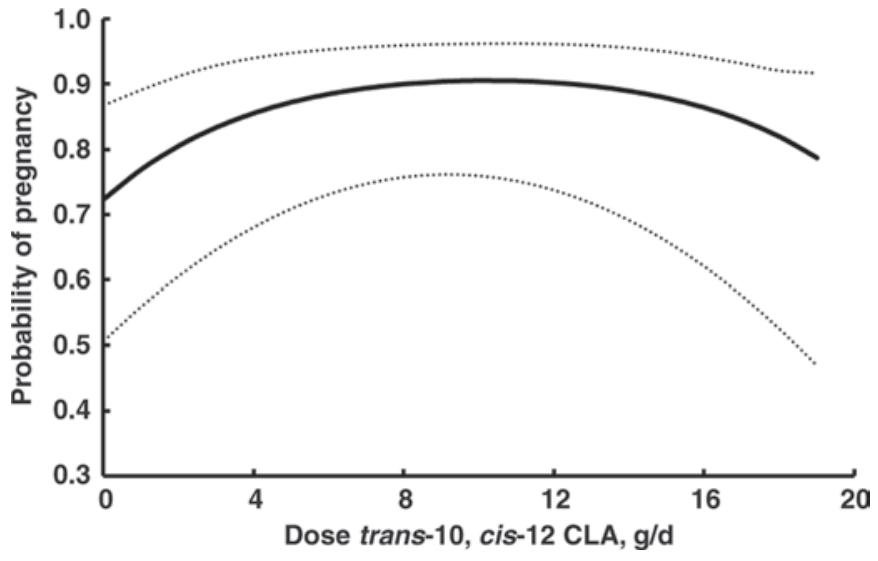

Figure 1. The relationship between dose of trans-10, cis-12 conjugated linoleic acid (CLA) and the probability of cows becoming pregnant. The quadratic dose response relationship was generated using logistic regression and is based on individual cow data $(\mathrm{n}=212)$ from 5 studies. The solid line represents the model-predicted relationship and dotted lines represent 95\% confidence intervals.

quadratic polynomial with linear term $(P=0.004)$ and quadratic term $(P=0.03$; Figure 1$)$. The quadratic model (Figure 1) predicts that animals receiving no CLA supplementation had $72 \%$ probability of becoming pregnant compared with the maximum probability of $91 \%$ for animals receiving $10.1 \mathrm{~g} / \mathrm{d}$ of trans-10, cis- 12 CLA.

Survival analysis for time to conception was evaluated using the Cox proportional hazards model, with results demonstrating significant CLA $(P<0.01)$ and study effects $(P=0.04)$. Additionally, linear $(P<0.01)$ and quadratic effects $(P=0.02)$ were observed in modeling time to pregnancy as a function of dose of trans-10, cis-12 CLA. The model for the hazard function of a cow conceiving was

$$
\begin{aligned}
h_{i}(t)= & h_{0}(t) \exp \left(0.399 x_{i 1}-0.339 x_{i 2}+0.216 x_{i 3}-0.090 x_{i 4}\right. \\
& \left.-0.185 x_{i 5}+0.049 \text { dose }-0.0059(\text { dose }-5.94)^{2}\right) .
\end{aligned}
$$

In this model, $x_{i 1}$ to $x_{i 5}$ represent estimates for Bernal-Santos et al. (2003), Castañeda-Gutiérrez et al. (2005), de Veth et al. (2005), Castañeda-Gutiérrez et al. (2007), and Mann et al. (2007), respectively (SE for study effects were $0.1843,0.1797,0.1412,0.1591$, and 0.1758 , respectively). Based on the Cox model, the relationships between DIM and the cumulative probability of pregnancy predicted for cows not receiving CLA and cows receiving the optimum CLA dose are presented in Figure 2. Using the optimal dose of trans-10, cis-12 CLA predicted by this model $(10.1 \mathrm{~g} / \mathrm{d})$, the median time to pregnancy was decreased to 105 DIM, which was $38 \mathrm{~d}$ less than for cows receiving no CLA (143 DIM). 


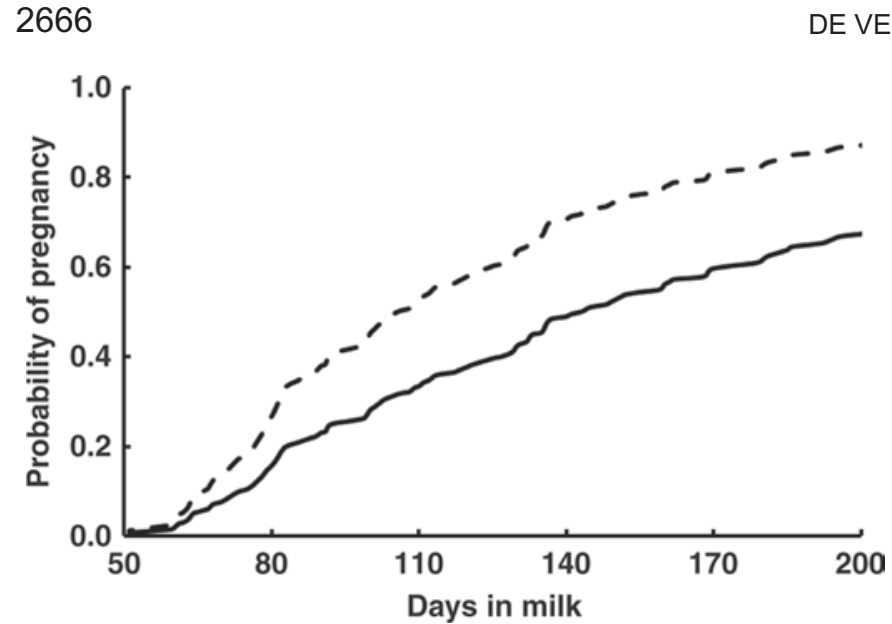

Figure 2. The relationship between DIM and the cumulative probability of becoming pregnant for cows receiving no conjugated linoleic acid (CLA) supplement (solid line) and cows receiving an optimum dose of CLA (dashed line). The Cox proportional hazards model predicted an optimum dose of $10.1 \mathrm{~g} / \mathrm{d}$ trans-10, cis-12 CLA based on individual cow data $(\mathrm{n}=212)$ from 5 studies.

In the parametric model, the log-normal distribution provided the best parametric fit for the time to conception, with a significant overall CLA effect observed $(P$ $<0.01)$. The log-normal describes a first increasing and then decreasing hazard function (Lee and Go, 1997); the probability of pregnancy increased from 50 DIM until it reached a peak at about the median time to conception, and then decreased thereafter. The log-normal model for time to conception also showed a linear decrease $(P=0.01)$ and a quadratic trend for an increase $(P=$ $0.06)$ as the dose of trans-10, cis-12 CLA increased. The parametric model for trans-10, cis-12 CLA dose was

$$
\begin{aligned}
\log \left(T_{i}\right)= & 4.931-0.192 x_{i 1}+0.192 x_{i 2}-0.096 x_{i 3}+0.006 x_{i 4} \\
& +0.091 x_{i 5}-0.021 \text { dose }+0.002(\operatorname{dose}-5.94)^{2}
\end{aligned}
$$

In the parametric model, the study effect was significant $(P=0.03)$ and $x_{i 1}$ to $x_{i 5}$ represent estimates for Bernal-Santos et al. (2003), Castañeda-Gutiérrez et al. (2005), de Veth et al. (2005), Castañeda-Gutiérrez et al. (2007), and Mann et al. (2007), respectively (SE for study effects were $0.0891,0.0839,0.0685,0.0763$, and 0.0856 , respectively). There was no dose by study interaction and the optimum dose predicted by this model was $10.5 \mathrm{~g}$ of trans-10, cis-12 CLA/d; therefore, to assess the effect of CLA on timing of pregnancy, the mean probability of pregnancy across the 5 studies for cows receiving no CLA and cows receiving the optimum trans-10, cis-12 CLA dose was plotted against DIM (Figure 3). The confidence intervals (CI) do not overlap after 80 DIM, indicating that not supplementing with CLA and supplementing with the optimal CLA dose differ $(<0.05$ level of significance). The overlap in
CI up to 80 DIM occurs because of the relatively low number of events occurring before this time point. Consistent with the relationship obtained using the Cox model, estimates from the parametric model indicated that the median time to pregnancy was decreased by $34 \mathrm{~d}$ for cows receiving the optimal dose of CLA when compared with cows not receiving supplemental CLA (117 vs. 151 DIM, respectively). Additionally, the curve for the probability of a cow becoming pregnant when receiving no CLA was less than the $95 \%$ confidence interval for the optimal CLA dose (Figure 3).

For time to first ovulation, neither the Cox proportional hazards model nor the parametric model found a study effect ( $P=0.74$ and 0.90 , respectively), and therefore the study effect was removed for the survival analysis. The Cox model did not find a significant overall CLA effect $(P=0.18)$. However, survival analysis with the parametric model for time to ovulation indicated there was a significant overall CLA effect $(P$ $=0.05)$ and quadratic term $(P=0.02)$ as a function of trans-10, cis-12 CLA dose. The model predicted a quadratic decrease in DIM until first ovulation as dose of trans-10, cis-12 CLA increased to the optimum (8.0 $\mathrm{g} / \mathrm{d})$. The parametric model for trans-10, cis-12 CLA dose was

$$
\log \left(T_{i}\right)=3.40-0.0065 \text { dose }+0.004(\text { dose }-7.17)^{2} .
$$

The mean probabilities for first ovulation of cows receiving no CLA and cows receiving the optimum trans-10, cis-12 CLA dose were plotted against DIM to assess the effect of CLA on time to first ovulation

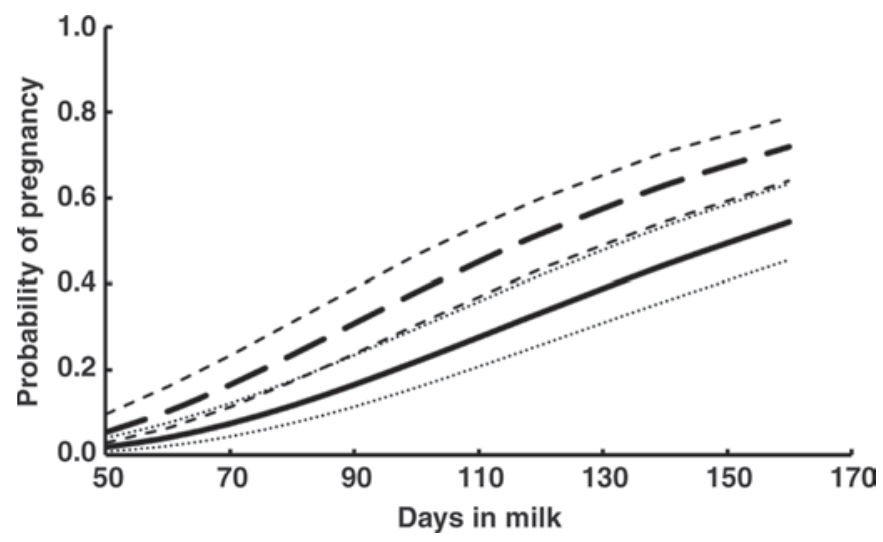

Figure 3. The relationship between DIM and the cumulative probability of becoming pregnant for cows receiving no conjugated linoleic acid (CLA) supplement (solid line) and cows receiving an optimal dose of CLA (long-dash line). The parametric model predicted an optimum dose of $10.5 \mathrm{~g} / \mathrm{d}$ trans-10, cis-12 CLA from individual cow data (n $=212$ ) from 5 studies and the $95 \%$ confidence intervals for no CLA supplement and optimal CLA dose are represented by the dotted lines and short-dash lines, respectively. 


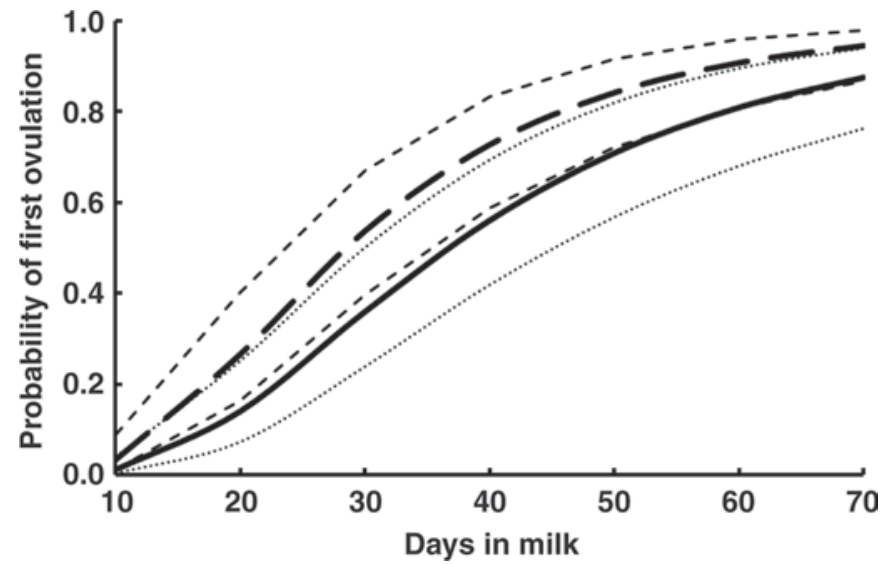

Figure 4. The relationship between DIM and the cumulative probability of first ovulation for cows receiving no conjugated linoleic acid (CLA) supplement (solid line) and cows receiving an optimal dose of CLA (long-dash line). The parametric model predicted an optimum dose of $8 \mathrm{~g} / \mathrm{d}$ trans-10, cis-12 CLA from individual cow data $(\mathrm{n}=76)$ from 2 studies and the $95 \%$ confidence intervals for no CLA supplement and optimal CLA dose are represented by the dotted lines and short-dash lines, respectively.

(Figure 4). The CI overlap considerably; for each dose, however, the CI do not cross the other dose's time to ovulation prediction. The parametric model indicated that supplementation with the optimal CLA dose decreased the median time to first ovulation compared with no CLA supplementation (29 vs. 37 DIM, respectively).

\section{DISCUSSION}

A trial designed with large numbers of animals is one approach that is used to assess effects of a particular treatment on reproductive performance. Nonetheless, such studies tend to be conducted under situations (e.g., commercial farms) that present challenges for reliable collection and analysis of data, and are ill suited to determining mechanisms or mode of action of particular treatments (St-Pierre and Jones, 1999). A second approach to ensure sufficient power for analysis is to conduct an integrated analysis of multiple studies or herds to evaluate changes in reproductive performance (Gillund et al., 2001). Analysis of multiple studies may also improve the precision in estimation of doseresponse relationships. Our analysis used the second approach with the objective of evaluating the effects of CLA supplementation on reproductive variables. Independently, 4 of the 5 studies had reported trends toward increased pregnancy rates and so an approach which combined data from all studies allowed for a detailed evaluation of the dose effects of CLA on reproductive performance. The survival analysis to evaluate time to pregnancy and first ovulation used both semi- parametric (Cox) and parametric (log-normal) models. The Cox model was used because it is a more robust model that makes no assumptions on the distribution of survival times. The parametric model was used because the assumptions were fulfilled and as it generates more precise estimates of the parameters. The consistency in the results derived from these models for time to pregnancy and first ovulation provides confidence in the estimated effect of supplementing trans-10, cis-12 CLA on these reproductive variables.

The analysis found that supplementation of trans-10, cis-12 CLA was associated with an increase in the probability of cows becoming pregnant and a decrease in the time to conception with increasing dose. There was a quadratic effect of CLA dose on pregnancy, increasing up to an optimum dose of $10.1 \mathrm{~g} / \mathrm{d}$ trans -10 , cis-12 CLA, after which the beneficial effects of CLA decreased. Likewise, survival analysis for time to conception also found a quadratic effect of CLA dose, with an optimum dose to decrease time to conception similar to that predicted to increase overall pregnancy. Survival analysis provides a more reliable estimation of the effect of CLA on pregnancy because it accounts for the rate over time at which cows conceive and this has a large effect on the economic cost of reproduction (Esslemont and Kossaibati, 2002). To our knowledge, the current study is the first multi-study analysis of the effects of CLA on reproduction in cattle or, in fact, any animal. Importantly, our analysis has provided an indication of the optimum dose level of trans-10, cis-12 CLA (approximately $10 \mathrm{~g} / \mathrm{d}$ ) for improving pregnancy in lactating dairy cows.

Our objective for time to first ovulation was to find the optimal dose and response function to CLA; however, only 2 of the 5 studies determined time to first ovulation (estimate based on plasma progesterone levels). Using a parametric model, a quadratic dose response was predicted for the time to first ovulation and this response was similar in nature to that seen for overall probability of pregnancy and time to conception. Increasing trans-10, cis-12 CLA supplementation led to an 8-d decrease in time to first ovulation at the predicted optimal dose of $8.0 \mathrm{~g} / \mathrm{d}$. This optimal dose was slightly lower (by approximately $2 \mathrm{~g} / \mathrm{d}$ ) than that predicted to maximize pregnancy with CLA; this difference and the borderline significance of the result of the time to ovulation analysis is likely caused by the smaller data set that was available for predicting time to first ovulation. The similarity in the profile of the response to trans-10, cis-12 CLA for both time to first ovulation and time to conception is consistent with the strong link between the 2 variables previously reported by Darwash et al. (1997). When monitoring the reproductive performance of 1,243 British Friesian cows, these 
authors reported a strong correlation between time to first ovulation and time to conception. These results have been confirmed by further studies (Butler, 2001; Wathes et al., 2007) and indicate that early establishment of ovarian activity is an important component of reproductive fecundity.

Because trans-10, cis-12 CLA decreases milk fat synthesis in a significant and predictable manner (de Veth et al., 2004), CLA could be applied as a management tool to spare energy, and therefore decrease the extent of negative energy balance after parturition in the lactating dairy cow (Griinari and Bauman, 2006). This use of CLA supplements is of interest because of the direct link between the degree of negative energy balance post-calving and subsequent fertility (Butler, 2000). However, few CLA studies have observed an improvement in energy balance of lactating dairy cows after calving, and the 5 studies used for the current analysis did not report any effect of CLA supplementation on net energy balance. This might be explained by repartitioning of nutrients toward milk protein and milk lactose synthesis and that the calculation of net energy balance involves crude estimates of nutrient intake and changes in body weight. Despite the absence of a change in net energy balance in the 5 studies used in the current analysis, changes in metabolic and endocrine signaling may be occurring with CLA-induced milk fat depression in the early lactation dairy cow. The repartitioning of nutrients toward milk protein and lactose synthesis at the mammary gland and the absence of changes in plasma NEFA concentrations with CLA supplementation (despite decreases in mammary uptake of fatty acids) indirectly suggests changes in nutrient signaling. One potential candidate is IGF-I, because its plasma levels are directly related to energy status in the cow (Butler, 2000; Wathes et al., 2007; Fenwick et al., 2008).

Recently, Castañeda-Gutiérrez et al. (2007) reported that plasma IGF-I levels were increased when supplemental trans-10, cis-12 CLA was provided to earlylactating dairy cows. Insulin-like growth factor-I promotes ovarian follicular development and Taylor et al. (2004) reported that cows with higher levels of IGF-I were more likely to conceive in the first $12 \mathrm{wk}$ of lactation. Additionally, plasma concentrations of IGF-I have been shown to be highly correlated to plasma estradiol concentrations (Butler, 2000). Estradiol produced by the growing follicle triggers the events leading to the LH surge and first ovulation, and recently CastañedaGutiérrez et al. (2007) reported trends for increases in concentrations of estradiol and its precursor androstendione (relative to progesterone) in nonatretic follicles from cows receiving trans-10, cis-12 CLA. Future research is needed to evaluate what effects CLA may have on both the somatotropic and reproductive axes in the early-lactation dairy cow.

Although the current multi-study analysis has provided evidence of the effect of trans-10, cis-12 CLA supplementation on reproductive performance of lactating dairy cows, several factors need further evaluation. Presently, the most favorable application time relative to calving and most effective length of application still needs to be determined. It seems likely that CLA supplementation should start at, or before, calving to have the highest probability of decreasing the time to first ovulation. Also, in the majority of studies included in this analysis, CLA supplementation was terminated before the period of time when the majority of conceptions occurred, indicating that the benefits of CLA on reproduction may last beyond the actual period of application. Additionally, factors such as parity and type of rumen protection method for CLA were not considered in the current analysis and these will need to be further examined. However, independent of the importance of these factors, the current multi-study analysis estimated that time to conception was decreased by $34 \mathrm{~d}$ when supplementing an optimal dose of trans-10, cis-12 CLA to early-lactation dairy cows. The economic cost for each extra day until conception (days open) for a lactating dairy cow has been estimated to vary between $\$ 0.81$ and $\$ 13.31$ in the United States (de Vries et al., 2005) and $£ 2.41$ to $£ 6.52$ in the UK (Esslemont and Kossaibati, 2002), with the cost increasing as DIM advances. Because of the economic value of decreasing time to conception and the extent of the improvement determined in the current analysis, further research is warranted to improve the understanding of the utility of CLA supplements to enhance reproductive performance in lactating dairy cows.

\section{CONCLUSIONS}

The potential for strategic supplementation of unsaturated fatty acids to improve reproductive performance has gained considerable interest because fertility of lactating dairy cows continues to decline. Our approach used a multi-study analysis to determine the effects of CLA on time to first ovulation and conception and overall success of pregnancy. Overall, there was a strong concordance in both the nature of the response and the predicted optimal dose of trans-10, cis-12 CLA supplementation across the 3 reproductive variables assessed. Time to conception and overall pregnancy success were predicted to be optimized at a dose of approximately $10 \mathrm{~g}$ of trans-10, cis-12 CLA/d. Further research is needed to verify and extend these results to establish the interval and duration of CLA supplementation to improve reproductive performance. 


\section{ACKNOWLEDGMENTS}

The authors greatly acknowledge the assistance of Euridice Castañeda-Gutiérrez (Cornell University) in compiling the database used for analysis of CLA effects on reproduction and Cristina Lanzas (Cornell University) for reviewing the manuscript.

\section{REFERENCES}

Bauman, D. E., J. W. Perfield II, K. J. Harvatine, and L. H. Baumgard. 2008. Regulation of fat synthesis by conjugated linoleic acid: Lactation and ruminant model. J. Nutr. 138:403-409.

Bernal-Santos, G., J. W. Perfield II, D. M. Barbano, D. E. Bauman, and T. R. Overton. 2003. Production responses of dairy cows to dietary supplementation with conjugated linoleic acid (CLA) during the transition period and early lactation. J. Dairy Sci. 86:3218-3228

Butler, W. R. 2000. Nutritional interactions with reproductive performance in dairy cattle. Anim. Reprod. Sci. 60-61:449-457.

Butler, W. R. 2001. Nutritional effects on resumption of ovarian cyclicity and conception rate in postpartum dairy cows. Pages 133-145 in Brit. Soc. Anim. Sci. Occasional Publication No. 26, Vol. 1. BSAS, Edinburgh, UK.

Butler, W. R. 2003. Energy balance relationships with follicular development, ovulation and fertility in postpartum dairy cows. Livest. Prod. Sci. 83:211-218.

Castañeda-Gutiérrez, E., B. C. Benefield, M. J. de Veth, N. R. Santos, R. O. Gilbert, W. R. Butler, and D. E. Bauman. 2007. Evaluation of the mechanism of action of conjugated linoleic acid isomers on reproduction in dairy cows. J. Dairy Sci. 90:4253-4264.

Castañeda-Gutiérrez, E., T. R. Overton, W. R. Butler, and D. E. Bauman. 2005. Dietary supplements of two doses of calcium salts of conjugated linoleic acid during the transition period and early lactation. J. Dairy Sci. 88:1078-1089.

Chagas, L. M., J. J. Bass, D. Blache, C. R. Burke, J. K. Kay, D. R. Lindsay, M. C. Lucy, G. B. Martin, S. Meier, F. M. Rhodes, J. R. Roche, W. W. Thatcher, and R. Webb. 2007. New perspectives on the roles of nutrition and metabolic priorities in the subfertility of high-producing dairy cows. J. Dairy Sci. 90:4022-4032.

Cox, D. R. 1972. Regression models and life tables. J. R. Stat. Soc. [Ser A] B34:187-220.

Darwash, A. O., G. E. Lamming, and J. A. Woolliams. 1997. The phenotypic association between the interval to post-partum ovulation and traditional measures of fertility in dairy cattle. Anim. Sci. 65:9-16.

de Veth, M. J., J. M. Griinari, A. M. Pfeiffer, and D. E. Bauman. 2004. Effect of CLA on milk fat synthesis in dairy cows: Comparison of inhibition by methyl esters and free fatty acids, and relationships among studies. Lipids 39:365-372.

de Veth, M. J., W. M. van Straalen, W. Koch, T. Keller, R. Hayler, and A. M. Pfeiffer. 2005. Effect of CLA dose on milk production in early lactation dairy cows. J. Dairy Sci. 88(Suppl. 1):220. (Abstr.)

de Vries, A., J. van Leeuwen, and W. T. Thatcher. 2005. Economics of improved reproductive performance in dairy cattle. Florida Cooperative Extension Service AN156, Institute of Food and Agricultural Sciences, University of Florida, Gainesville.

Esslemont, D., and M. Kossaibati. 2002. The Costs of Poor Fertility and Disease in UK Dairy Herds-Trends in DAISY Herds Over 10 Seasons. DAISY Research Report No. 5. Intervet UK Limited, Milton Keynes, UK.

Fenwick, M. A., R. Fitzpatrick, D. A. Kenny, M. G. Diskin, J. Patton, J. J. Murphy, and D. C. Wathes. 2008. Interrelationships between negative energy balance (NEB) and IGF regulation in liver of lactating dairy cows. Domest. Anim. Endocrinol. 34:31-44.

Gillund, P., O. Reksen, Y. T. Grohn, and K. Karlberg. 2001. Body condition related to ketosis and reproductive performance in Norwegian dairy cows. J. Dairy Sci. 84:1390-1396.

Griinari, J. M., and D. E. Bauman. 2006. Milk fat depression: Concepts, mechanisms and management applications. Pages 383411 in Ruminant Physiology: Digestion, Metabolism and Impact of Nutrition on Gene Expression, Immunology and Stress. K. Sejrsen, T. Hvelplund, and M. O. Nielsen, ed. Wageningen Academic Publishers, Wageningen, the Netherlands.

Lee, E. T., and O. T. Go. 1997. Survival analysis in public health research. Annu. Rev. Public Health 18:105-134.

Lucy, M. C. 2001. Reproductive loss in high-producing dairy cattle: Where will it end? J. Dairy Sci. 84:1277-1293.

Lucy, M. C. 2003. Mechanisms linking nutrition and reproduction in postpartum cows. Reprod. Suppl. 61:415-427.

Mann, G. E., A. L. Lock, D. E. Bauman, and N. R. Kendall. 2007. Reproductive function in dairy cows fed a lipid encapsulated conjugated linoleic acid supplement. J. Dairy Sci. 90(Suppl 1):401. (Abstr.)

Santos, J. E. P., T. R. Bilby, W. W. Thatcher, C. R. Staples, and F. T. Silvestre. 2008. Long chain fatty acids of diet as factors influencing reproduction in cattle. Reprod. Domest. Anim. 43(Suppl. 2):2330 .

St-Pierre, N. R., and L. R. Jones. 1999. Interpretation and design of nonregulatory on-farm feeding trials. J. Anim. Sci. 77(Suppl. 2):177-182.

Staples, C. R., J. M. Burke, and W. W. Thatcher. 1998. Influence of supplemental fats on reproductive tissues and performance of lactating cows. J. Dairy Sci. 81:856-871.

Staples, C. R., and W. W. Thatcher. 2006. Effects of fatty acids on reproduction of dairy cows. Pages 229-256 in Recent Advances in Animal Nutrition 2005. P. C. Garnsworthy and J. Wiseman, ed. Nottingham University Press, Nottingham, UK.

Taylor, V. J., Z. Cheng, P. G. Pushpakumara, D. E. Beever, and D. C. Wathes. 2004. Relationships between the plasma concentrations of insulin-like growth factor I in dairy cows and their fertility and milk yield. Vet. Rec. 155:583-588.

Wathes, D. C., N. Bourne, Z. Cheng, G. E. Mann, V. J. Taylor, and M. P. Coffey. 2007. Multiple correlation analyses of metabolic and endocrine profiles with fertility in primiparous and multiparous cows. J. Dairy Sci. 90:1310-1325. 